\title{
consulting with faculty: necessary and possible
}

\section{DAVID A. KOPPLIN LOUIS C. RICE}

David A. Kopplin, formerly Associate Director of Counseling Services at the University of Michigan in Ann Arbor, is presently Assistant Professor of Psychology at that institution. Louis C. Rice is Director of Preprofessional Counseling and Associate Director of Academic Advising for the College of Literature, Science and the Arts at the same institution.

Warnath has stated that "the college counseling center is in a paradoxical position-the greater its investment in the counseling of individuals, the less general impact it has on the solution of student problems" (1971, p. 63). Psychological counselors see only a small percentage of troubled college students. The primary care-givers are teaching staff, student personnel staff, and peer
Through case and program consultation with counselors, faculty can become more effective in helping troubled students. In this article the authors offer examples of counseling agency consultation with faculty individuals and groups. They identify and evaluate conditions that inhibit consultation as well as circumstances that facilitate it, with the view that effective use of consultation may affect the future development of university counseling services.

counselors to whom students come regularly with personal difficulties. Through consultation programs, however, counseling staff can enable campus caregivers to become more sensitive to students and more effective helpers. It is our contention that mental health consultation (Caplan 1970; Singh 1971) provides a model for developing an approach to college support services in 
which the counseling professional can extend the counseling mission. Our work with individual faculty has focused on both client-centered case consultation and consultee-centered case consultation, while work with faculty groups in schools and colleges has included program-centered and administrative-centered consultation (Caplan 1963).

\section{OVERCOMING THE OBSTACLES}

Because many psychological counselors have cultivated an image as "specialists," some faculty have felt that they need not, and perhaps should not, involve themselves in the personal problems of students; counseling requires an expertise possessed only by the professional. Faculty members thus avoid counseling and quickly refer troubled students to specialists. Moreover, the typical university structure isolates professional counselors from the teaching faculty both physically and organizationally. This isolation discourages contact, communication, and mutual consultation with teaching faculty.

The problem is further compounded by the growing complexities and competing demands of teaching, counseling, research, and publication. A highly trained and specialized professor with a particular professional identity and interpersonal style may have trouble assuming the role of counselor. Indeed, specialization appears to promote isolation, competitiveness, and a reluctance to assume nonacademic responsibilities to students. Because these obstacles form barriers to consultation as well as to counseling, they are the very issues to which consultation is directed.

Mental health consultation can increase the sensitivity and ease with which teachers relate to those in need of help. This interaction process respects the particular roles of the professionals involved-in this case, teacher and counselor. Consultation has been defined as the application of psychological change techniques to a problem situation in which an individual or a group with specialized resources in the problem area and an individual or a group with authority and responsibility for action in the problem area collaborate through interpersonal communication (Rhodes 1960). A change in human behavior can mean a change in the perception of the problem or a change in feelings, behaviors, and skills in dealing with the problem. Any or all of these changes may be included in the development of consultation objectives.

Despite the limitations imposed by the climate of university specialization today, it is possible to develop case consultation programs. At least two situations can provide an opportunity for consultation with faculty: an inquiry from an individual professor about a particular student or an invitation from an administrator or teacher to work with the faculty of a school or college.

\section{CONSULTATION WITH INDIVIDUAL FACULTY MEMBERS}

In the first case, consultation begins when a professor contacts a counselor about an individual student who has personal problems. The faculty member, for example, may be uncomfortable with a student's anxiety about completing course requirements due to some form of stress in the student's interpersonal relationships and may, as a result, seek assistance from a professional counselor.

A variety of counselor responses are available. The counselor can agree to see the student, in which case contact with the professor quickly terminates. Or the counselor may indicate that another counselor is on duty and is handling referrals; again, contact with the professor is rapidly terminated. However, the counselor might explore the dynamics of the student's problem and, if appropriate, assist the professor in working 
with the student. The counselor may or may not need to see the student; in either case, this last approach initiates the development of a consultative relationship.

The counselor's initial response conditions the potential consultee by indicating the kind of relationship the counselor prefers with interested faculty and thus influences their future relationship. If a counselor simply accepts the referral, the caller may assume that a referral was appropriate and that the counselor is not interested in the professor's perceptions but prefers to make an independent, professional evaluation. The caller may well conclude that further involvement with the student's personal problems is unnecessary or even inappropriate. No doubt, the student would also sense a withdrawal of interest.

At the other extreme, consultation might begin without a contract or an invitation. In this case, professors who are not aware of the availability of consultation in a counseling agency might react adversely to any premature attempts at consultation. Failure to anticipate such faculty expectations about the counseling service may be construed as rejection rather than assistance when the counselor shifts to a consultant's role. Thus, in beginning a process of consultation, it is important to move gradually from the traditional role of accepting referrals and giving direct counseling to the role of a consultant. Feedback after referral, within the limits of confidentiality, fosters effective consultation relationships with faculty.

The following guidelines are suggested as initial responses to a referral by an academic colleague. First, offer immediate interest in and acceptance of the request for referral or referral assistance. Second, exercise caution in probing for information beyond that which the referrer freely presents. Third, explore all leads sufficiently to allow the referrer full expression of the problem and to build a relationship. If a workable relationship is established, the faculty member and counselor can proceed to clarify the student's problem and determine whether a referral to a counselor is in fact necessary.

The trust that a counselor places in a faculty member's abilities can promote the faculty member's sense of being a personal care-giver, and under such circumstances the professor may feel encouraged to use his or her unique skills and role identity. The faculty member who believes that the informal consultation was beneficial and that the counselor responded as an interested colleague may request future consultation as well as recommend a similar use of the counseling service to colleagues. Even though

"Because many psychological counselors have cultivated an image as 'specialists,' some faculty have felt that they need not, and perhaps should not, involve themselves in the personal problems of students."

not all referrals lead to significant consultation, those that do lay the foundation for more extensive consultation programs with faculty.

\section{CONSULTATION PROGRAMS WITH SCHOOLS: TWO EXAMPLES}

Beyond occasional consultation through contact with individual faculty, opportunities occur for developing consultation programs in particular schools or colleges. For example, faculty members or administrators may express interest or concern about their school or college counseling program, or the counselor may informally contact deans, faculty, and student personnel coordinators about faculty interest in counseling con- 
sultation. The consultant should remember, however, that ultimately the initiative must rest with the consultee, since successful consultation begins with a recognized need for assistance and a willingness to enlist that assistance. This is no less true of groups than of individuals. Following are two examples of a counseling agency's attempt at formal school and college consultation, one unsuccessful, the other successful.

\section{Unsuccessful Consultation}

In school A, contact with the counseling service was initiated by a faculty member who had an interest in student counseling. Two agency counselors talked with him about student problems and the general provisions for counseling in the university. Subsequently, a discussion meeting was proposed to present coun-

\section{"In beginning a process of con- sultation, it is important to move gradually from the traditional role to the role of a consultant."}

seling issues to the school's faculty in order to increase awareness of campus resources and supportive services for students, identify those student needs and problems that the faculty and staff recognized, and make counselors available for consultation and inservice training.

A panel composed of representatives from the principal counseling and mental health services on campus was to provide information about counseling resources. The faculty members were then to divide into seminar groups to discuss their counseling concerns. Unfortunately, a prior budget issue preempted much of the agenda, and there was time for only the formal presentations and the question-and-answer period. More personal and informal discussion was precluded. After the presentation the faculty contact asked the agency to submit a formal consultation proposal; the proposal that was developed included a systematic program of faculty seminars and consultation, the identification of faculty coordinators, and a cost estimate. It was submitted to the executive committee of the school for consideration, but we received no further contact from the school or faculty representatives regarding interest in a formal consultation program.

Several factors may have contributed to difficulty in implementing this model. First, only one faculty member displayed a high interest in counseling issues and an energy for program development, and his influence was an unknown. Second, the largest and most influential department of the school had no member among the initial contacts with the school. Third, no initial contacts were made with the administration, and consequently the dean's support was not won. Fourth, the counseling staff had no available time to identify other potentially interested administrators and faculty. Fifth, the restricted format of our initial presentation depersonalized potential relationships instead of enhancing counselor contact with faculty. Sixth, in view of the lack of clearly identified faculty and administrative linkages, the consultation proposal appears to have been too ambitious and premature.

\section{Successful Consultation}

In school B, initial informal contact with the counseling service involved a staff member in the school and a staff member in the agency who were personal acquaintances. The school staff member hoped to develop a faculty counseling program, and he met with a small group of influential faculty and student representatives to give legitimacy to the consultant. The agency staff member was interested and was available to assist the school's faculty in exploring 
issues surrounding the development of a counseling program.

This group identified the following objectives for a series of training sessions: (a) the promotion of more meaningful student-faculty contact; (b) increased faculty awareness of student needs and student development; (c) reduction of stratified superiorsubordinate relationships between instructors and students; and (d) the enhancement of student professional development in certain areas of knowledge, skill, and attitude. The program was introduced to the school, a faculty chairperson was designated, and interested faculty became involved on a voluntary basis in a series of monthly orientation and training programs. A counseling staff member assumed responsibility for the inservice training programs.

Implementation of the consultation program depended primarily on the effective involvement of faculty, particularly an influential faculty chairperson who personally contacted each of the twenty faculty counselors, soliciting their interest, involvement, and commitment. The consultant capitalized on their interest by conducting monthly training programs in the homes of faculty volunteers. The informal atmosphere was conducive to the exchange of ideas and the development of a group identity among the faculty counselors.

The training program was outlined by the founding group in the context of student-faculty dynamics and the school environment. The first training session was devoted to exploring the issues that faculty counselors identified as being important to them in their roles as counselors. The next session introduced the faculty counselors to student developmental concerns and student needs, particularly as these related to the demands of the school. Additional training sessions utilized counseling case studies, role playing, trigger films (Fisch 1972), and counseling theory position papers. Since the program's inception several years ago, it has been integrated into the operating procedures of the school. Continued contact has been maintained between the counseling consultant and representatives of the school.

A number of factors contributed to the success of this consultation model. First, the consultation developed as a result of individualized contact by influential personnel who gave legitimacy to the agency consultant. Second, interest in counseling issues existed among a small group of committed faculty. Third, a group of students from the school were involved in the formulation of the program, and the faculty responded to them by investing their own time and energy. Fourth, interested faculty convinced the school's administration of the appropriateness of this counseling project and indicated their willingness to work for its implementation. Fifth, a series of informal contacts with faculty were designed, and everyone committed one year to the program. Sixth, the consultant maintained close contact with a relatively small number of faculty who were interested and willing to commit themselves to the development of the program. Seventh, the counseling agency released time for a single staff member, primarily responsible to the faculty chairperson of the program, to coordinate this project. The result was the evolution and continuity of a good working relationship.

\section{CONCLUSIONS AND IMPLICATIONS}

Mental health consultation has many of the qualities of individual counseling practice. Users tend to select consultants by individual rather than agency reputation. This fact may be less significant in other professions, but in counseling and consultation a special relationship must evolve in order to allow the client or counselee to expose inner feelings and 
concerns. Thus, in consultation as in counseling, a substitute professional is usually not acceptable after the relationship with the first professional has developed.

Our experience suggests that, for effective faculty consultation, it is important to choose individual staff carefully so that personal relationships can develop with the various subunits of the campus. This implies that a staff member must exercise caution in attempting to transfer consulting contracts to other counselors. If a transfer is made, it is likely that when school or department members have a problem, they will call (or wish they could call) the initial consultant. The use of staff members in consulting roles depends on their capacity and skill in creating their own relationships with potential consultees, as they do with their own counseling clients.

The priority that a counseling center gives to consultation depends on political and practical issues. Staff may avoid consultation opportunities because direct work with clients gives more immediate gratification. We urge a modification of the traditional direct counseling approach for four reasons. First, there is growing recognition that there will never be enough mental health professionals to treat all for whom assistance is appropriate; consultation can augment the ability of an agency to work effectively with greater numbers of the population. Second, consultation builds relationships that ultimately can be helpful in changing institutional and environmental causes of student difficulties. Third, since the essentials of good teaching, counseling, and consulting are closely related, counselors as well as faculty benefit from the increased contact and communication that consultation can provide (Chickering 1969; Feldman \& Newcomb 1969; Sanford 1962). Fourth, as counseling centers come increasingly under attack in the current higher education financial crisis, they will need solid support from faculty to maintain their financial priorities. Consultation is perhaps the best way to enlist the active support of faculty members, because it makes them direct beneficiaries of the counseling service. The faculty's longterm advocacy for counseling activities will generally outlast the testimonials of students who were helped through individual counseling.

Consultation offers a way to extend the growth of the counseling services' mission and at the same time can insure the services' survival. Consequently, from several perspectives, there appears to be sufficient reason for thorough exploration and implementation of consultation with faculty for university counseling services.

\section{REFERENCES}

Caplan, G. Types of mental health consultation. American Journal of Orthopsychiatry, 1963, 33(3), $470-481$.

Caplan, G. The theory and practice of mental health consultation. New York: Basic Books, 1970.

Chickering, A. W. Education and identity. San Francisco: Jossey-Bass, 1969.

Feldman, K. A., \& Newcomb, T. M. The impact of college on students (Vols. 1 \& 2). San Francisco: Jossey-Bass, 1969.

Fisch, A. L. The trigger film technique. Improving College and University Teaching, 1972, 20(4), 286289.

Rhodes, W. C. Training in mental health consultation. Paper presented at the American Psychological Association Convention, Chicago, September 1960.

Sanford, N. (Ed.) The American college: A psychological and social interpretation. New York: Wiley, 1962.

Singh, R. K. J. Community mental health consultation and crisis intervention. Berkeley, Calif.: Book People, 1971.

Warnath, C. F. New myth and old realities. San Francisco: Jossey-Bass, 1971. 